\title{
Textos de divulgação científica na revista Pesquisa Fapesp: Análise do sincretismo em reportagem sobre AIDS
}

\author{
Texts of scientific dissemination in the Pesquisa Fapesp \\ magazine: Analysis of syncretism in AIDS reporting
}

\section{Textos de divulgación científica en la revista Pesquisa Fapesp: Análisis del sincretismo en los informes del SIDA}

\author{
(iD) Arnaldo Cortina \\ Universidade Estadual Paulista Júlio de Mesquita Filho (UNESP), Araraquara, São Paulo, \\ Brasil. \\ E-mail: arnaldo.cortina@unesp.br.
}

Resumo: Este trabalho pretende examinar o texto de divulgação científica para verificar como os sentidos constroem-se. Para tanto, propõe examinar a revista Pesquisa Fapesp, que, na percepção do projeto, é constituída por textos sincréticos, compreendidos como aqueles em que a linguagem verbal e a visual estabelecem relação de homologação para a produção do sentido global. A perspectiva teórico-metodológica por meio da qual será empreendida a investigação é a semiótica discursiva, que trata o texto verbo-visual como uma manifestação de sentido resultante do sincretismo de diferentes linguagens. Para atingir esse objetivo, o trabalho propõe, inicialmente, descrever e examinar a organização da revista Pesquisa Fapesp para entender como ela trata a divulgação científica e para qual interlocutor se dirige. Em segundo lugar, objetiva produzir a análise semiótica de uma reportagem da revista referida.

Palavras-chave: Discurso. Divulgação científica. Enunciação. Sincretismo. Texto. 
Abstract: This paper aims to examine the text of scientific dissemination to verify how the senses are constructed. To this end, it proposes to examine Pesquisa Fapesp magazine, which, in the perception of the project, corresponds a syncretic text, understood as those in which verbal and visual language establish a homologation relationship for the production of global meaning. The theoretical-methodological perspective from which the investigation will be undertaken is that of discursive semiotics, which treats the verb-visual text as a manifestation of meaning resulting from the syncretism of different languages. In order to achieve this goal, the paper initially proposes to describe and examine the organization of Pesquisa Fapesp magazine to understand how it deals with scientific dissemination and to which interlocutor it addresses. Secondly, it aims to produce the semiotic analysis of a report from the referred magazine.

Keywords: Enunciation. Scientific divulgation. Speech. Syncretism. Text.

Resumen: Este trabajo pretende examinar el texto de divulgación científica para verificar cómo se construyen los sentidos. Con este fin, propone examinar la revista Pesquisa Fapesp, que, en la percepción del proyecto, consiste en un texto sincrético, entendido como aquel en el que el lenguaje verbal y visual establece una relación de homologación para la producción de significado global. La perspectiva teórico-metodológica desde la que se llevará a cabo la investigación es la de la semiótica discursiva, que trata el texto verbo-visual como una manifestación de significado resultante del sincretismo de diferentes idiomas. Para lograr este objetivo, el trabajo propone, inicialmente, describir y examinar la organización de la revista Pesquisa Fapesp para comprender cómo se ocupa de la difusión científica y a qué interlocutor se dirige. En segundo lugar, tiene como objetivo producir el análisis semiótico de un informe de la revista antes mencionada.

Palabras clave: Discurso. Difusión científica. Enunciacion. Sincretismo. Texto.

Submetido em 20 de janeiro de 2020.

Aceito em 06 de maio de 2020.

Publicado em 16 de novembro de 2020. 
Textos de divulgação científica na revista Pesquisa Fapesp: Análise... Arnaldo Cortina

\section{Apresentação}

O propósito inicial de nossa pesquisa consiste em examinar a constituição dos textos verbo-visuais de reportagem da revista Pesquisa Fapesp, que lança um número a cada mês. Para ter uma ideia de como a revista está configurada, estabelecemos um córpus de análise que corresponde ao período de julho de 2016 a junho de 2017.

Uma vez que a maioria das reportagens de divulgação científica da revista em questão é constituída pela manifestação da linguagem verbal e visual, pretendemos verificar como se estabelecem as relações entre essas linguagens e como elas veiculam os sentidos dos textos. O trabalho toma por base a perspectiva teórico-metodológica da semiótica discursiva para examinar as questões relativas à constituição textual e ao fenômeno do sincretismo presente nas reportagens divulgadas pela revista.

Este artigo é composto por três partes para darmos conta de nosso objetivo central. Na primeira, observamos como a semiótica discursiva concebe a constituição do texto sincrético e quais suas bases teóricas para o tratamento do texto - para verificarmos como se configuram as reportagens da revista Pesquisa Fapesp enquanto textos sincréticos, ao mesmo tempo que discutimos como a revista se constitui como um veículo de divulgação científica para determinado público de leitores. Na segunda, apresentamos uma descrição do córpus da pesquisa e, além disso, mostramos a organização desse veículo de informação. Na terceira, propomos a análise de uma reportagem selecionada aleatoriamente entre as 12 revistas que compõem o córpus da pesquisa, que trata de um problema de saúde pública, o atendimento aos portadores do vírus HIV no Brasil e em outras partes do globo, com o intuito de discutir como o sentido se constitui nessa reportagem a partir da relação estabelecida pelo texto entre a linguagem verbal e a visual. 
Textos de divulgação científica na revista Pesquisa Fapesp: Análise... Arnaldo Cortina

\title{
2 Texto sincrético e a perspectiva da semiótica discursi- va para o tratamento do texto verbo-visual
}

O sentido do termo sincretismo está, desde sua origem, relacionado à noção de fusão. Segundo Houaiss (2009, p. 1748), a etimologia grega do vocábulo, sugkrētismós, oû, referia-se à "união de cretenses contra um adversário comum". Assim, o sentido de fusão inerente à palavra pode ser observado em diferentes áreas do conhecimento humano, tal como a religião, a filosofia, a antropologia, a sociologia. Em linguística o sincretismo refere-se à fusão de elementos distintos, tal como ocorre na fonologia (no caso da palavra "pato" [/pa'tU/], que corresponde à articulação em diferentes regiões do país) ou como na morfologia, a indistinção da forma, por exemplo, do verbo de primeira conjugação, no pretérito imperfeito, entre primeira e terceira pessoas do singular (eu cantava vs ele cantava). Em decorrência das propostas de Hjelmslev (2009), o sincretismo em semiótica, tal como explicitado em Greimas e Courtés (2008, p. 467), será definido da seguinte forma:

\begin{abstract}
Num sentido mais amplo, serão consideradas como sincréticas as semióticas que - como a ópera ou o cinema - acionam várias linguagens de manifestação; da mesma forma, a comunicação verbal não é somente de tipo linguístico: inclui igualmente elementos paralinguísticos (como a gestualidade ou a proxêmica), sociolinguísticos, etc. (grifo dos autores).
\end{abstract}

Para a semiótica discursiva, considerando ainda as propostas de Hjelmslev (2009), o texto corresponde a uma grandeza que pode ser manifestada por diversas substâncias. Dessa forma, o discurso, da ordem da forma, constitui-se em texto sempre que uma substância se manifesta. Greimas e Courtés (2008, p. 503) definem o processo de textualização da seguinte maneira: 
Textos de divulgação científica na revista Pesquisa Fapesp: Análise...

Sempre que o percurso gerativo é interrompido, ele dá lugar à textualização (linearização e junção com o plano de expressão): o texto obtido mediante esse procedimento equivale à representação semântica do discurso e pode - na perspectiva da gramática gerativa - servir de nível profundo às estruturas linguísticas que geram, por sua vez, estruturas linguísticas de superfície.

De acordo com a proposta teórico-metodológica da semiótica discursiva, o sentido, do ponto de vista do conteúdo, decorre de um percurso gerativo que compreende diferentes estruturas. Nosso intuito não é descrever as etapas do percurso gerativo do sentido, mas examinar como os elementos manifestados nas estruturas superficiais, que correspondem às projeções da enunciação, às figuras e aos temas, articulados aos componentes das demais instâncias desse mesmo percurso, manifestam-se na superfície textual.

Dessa forma, a reportagem da revista Pesquisa Fapesp é entendida como um texto em que se manifestam dois planos de expressão: o verbal e o visual. Esses dois planos de expressão veiculam um conteúdo que é apreendido pelo leitor do texto. Os conteúdos manifestados pelos dois planos de linguagem não são autônomos, no sentido de que o que está dito em um soma-se ao que é evidenciado pelo outro. Em verdade, segundo a concepção de sincretismo anteriormente apresentada, trata-se da fusão dos dois planos de expressão que corresponde a um único sentido manifestado pelo plano do conteúdo geral.

Embora as manifestações visuais que compõem o texto de reportagem da revista Pesquisa Fapesp funcionem como ilustrações das informações veiculadas pela linguagem verbal, sua função consiste em acentuar ou reforçar aquilo que é informado pelo componente verbal. Na maioria das vezes, os recursos visuais correspondem a fotografias, infográficos ou desenhos elaborados por uma equipe técnica com o intuito de tornar mais didática a divulgação da informação selecionada pelo texto da reportagem. Nesse senti- 
Textos de divulgação científica na revista Pesquisa Fapesp: Análise...

do, o propósito central da revista consiste em informar ao público a que se dirige, um público majoritariamente universitário, pertencente às diversas áreas do conhecimento, pesquisas concluídas ou em andamento produzidas por pesquisadores financiados ou não pela Fapesp. Como o intuito da revista é difundir as informações a esse público mais geral, propõe valer-se então do processo de didatização, divulgando por meio de uma linguagem mais acessível informações técnicas que não seriam compreendidas por aqueles que não estão acostumados à terminologia específica de determinadas áreas de conhecimento. Por essa razão, também, os textos de reportagens da revista Pesquisa Fapesp são produzidos por uma equipe de jornalistas, assessorada por cientistas que desenvolvem pesquisas sobre o tema próprio de cada uma delas. As reportagens veiculadas pela revista Pesquisa Fapesp nunca são produzidas pelo próprio cientista que realiza as investigações sobre as quais elas tratam.

Nesse sentido, portanto, o texto final da reportagem, produzido por esse enunciador que tem o propósito de divulgar de forma mais acessível as informações científicas, utiliza o elemento visual para compor a informação que pretende veicular, ao mesmo tempo que, por meio do emprego desse elemento visual, procura também atrair a atenção do leitor para aquilo que é manifestado no discurso. Entendemos que o sincretismo por meio do qual as reportagens da revista Pesquisa Fapesp organizam-se decorre de uma estratégia do enunciador para aproximar-se de seu enunciatário. Uma vez que os textos das reportagens devem tratar dos mais variados temas científicos, o processo de simplificação da linguagem é sustentado pelo recurso visual e torna mais evidentes certos conceitos e certas informações veiculadas. Em verdade, a semiótica visual faz parte do processo de didatização da informação porque pode oferecer ao leitor uma forma de entrada ao assunto do texto. Por outro lado, como podemos identificar na entrevista que realizamos com o editor-chefe da referida revista, a semiótica visual funciona também como um recurso estético que visa a estabelecer a adesão do leitor. 
Textos de divulgação científica na revista Pesquisa Fapesp: Análise... Arnaldo Cortina

\begin{abstract}
A reportagem é composta por texto e imagens. Há o objetivo de dar informações por meio da imagem, mas tem o objetivo de atrair o leitor também. Se estamos folheando a revista e vemos uma foto espetacular ou uma foto curiosa ou uma foto que remete a algo de nossa área, paramos para ler. "Por que esta imagem está aqui? Do que trata o texto?", são as perguntas óbvias. Ligamos uma coisa à outra. O objetivo é também chamar a atenção para o que queremos comunicar. Uma das coisas que mais me irrita é quando o pesquisador ou qualquer tipo de leitor diz, "Vocês fazem uma revista linda". Ouço muito isso. É difícil alguém me dizer, "As matérias que vocês estão fazendo são sensacionais". Nunca sei se quem chega para mim e diz "sua revista é linda", leu mesmo a revista. Eu sei que ele viu a revista. E sempre brinco com os colegas aqui na redação e digo: esse elogio para mim não diz nada. Por que as pessoas não se referem ao que leram? Algo como "tal e tal matéria são legais" ou o contrário "tal matéria ficou ruim porque vocês usaram um viés equivocado"1.
\end{abstract}

A entrevista realizada com Neldson Marcolin, editor-chefe da revista Pesquisa Fapesp, logo no início da pesquisa, teve por objetivo refletir sobre a prática da elaboração do texto global que corresponde aos diferentes números da revista selecionados para análise. Nosso interesse consistiu em conhecer como esse enunciador-elaborador do veículo de informação propõe os textos que produz. Foi por meio dessa entrevista inicial que pudemos conhecer a preocupação central da equipe que produz o periódico com a forma como divulgam os conhecimentos científicos para o público a que se dirige. Pudemos constatar que o cuidado com que são compostas as reportagens inclui o viés didático, que faz parte da construção das diferentes matérias, e a importância atribuída ao elemento visual, tanto para atrair o público para os assuntos científicos como para reforçar essa maneira de abordar os diferentes temas e torná-los mais acessíveis a seus leitores.

1 Trecho de entrevista concedida a este autor pelo editor-chefe da Revista Pesquisa Fapesp, Neldson Marcolin, em 12 de março de 2018, na sede da editora da revista. 
Textos de divulgação científica na revista Pesquisa Fapesp: Análise...

Arnaldo Cortina

Um dos primeiros semioticistas a examinar e a discutir a produção de sentido no texto visual foi Jean-Marie Floch, ainda nos anos 1980. Em Petites mythologies de l'œil et de l'esprit (FLOCH, 1985, p. 11), o autor afirma que

\begin{abstract}
Une approche sémiotique d'image et de l'art est possible, mais nous ne pensons pas qu'une telle approche « sémiotise » l'image ou l'art : l'image ou l'art ne sauraient être, selon nous, des objets sémiotiques, c'est-à-dire le résultat d'une construction effectuée par le semioticien. L'image, l'art, la peinture, la photographie, ne sont que des données, de phénomènes certes saisissables comme des ensembles signifiants - sinon la sémiotique ne les prendrait pas en considération - mais dont la définition, la détermination, et plus encore le statut, sont, le fait de découpages culturels, c'est-à-dire historiques et relatifs. ${ }^{2}$
\end{abstract}

Mais adiante, no mesmo texto anteriormente citado, Floch (1985, p. 12-13) considera ainda o seguinte:

[...] L'image, par exemple, ne sera pas, pour le sémioticien, le type même du signe iconique ou du message constitué de signes iconiques; au contraire, elle sera abordée comme un texte-occurrence, c'est-à-dire comme le résultat d'un processus complexe de productions du sens, dont les étapes, pour l'essentiel, ne sont pas différentes de celles du processus générant n'importe quel autre texte, linguistique ou non. Et l'iconicité ellemême sera finalement définie comme la production d'un effet de sens de "réalité », caractéristique non pas de tel langage ou de tel signe mais d'un certain type de discours exploitant les connotations sociales et, entre autres, ce que telle société pense de ses différents langages quant à leurs rapports respectifs à la « réalité ». [...] La sémiotique se veut une théorie de la

\footnotetext{
2 Uma abordagem semiótica da imagem e da arte é possível, mas não pensamos que tal abordagem "semiotize" a imagem ou a arte: a imagem ou a arte não poderiam ser, em nossa opinião, objetos semióticos, isto é, o resultado de uma construção realizada pelo semioticista. A imagem, a arte, a pintura, a fotografia são apenas dados, fenômenos certamente apreciáveis como conjuntos significativos - caso contrário, a semiótica não os levaria em consideração -, mas cuja definição, determinação e ainda mais o status são divisões culturais de fato, ou seja, históricas e relativas (tradução nossa).
} 
Textos de divulgação científica na revista Pesquisa Fapesp: Análise...

Arnaldo Cortina

signification à la fois structurale et générative : structurale en ce sens que, pour elle, les sens naît de la saisie des différences et qu'il s'agit dès lors de construire les systèmes de relations qui en rendent compte : les langages seront construits comme des systèmes de relations et non comme des systèmes de signes (le "structuralisme » sémiotique doit en effet être compris comme l'assomption d'un double héritage épistémologique, saussurien e hjelmslevien); générative, la sémiotique l'est en ce sens qu'elle se représente les sens comme le résultat d'un processus de production, de complexification croissante, représentable sous la forme de paliers ou de niveaux plus ou moins profonds ou superficiels ; en revanche, l'approche générative, en sémiotique , ne peut pas être assimilée - sinon par abus de langage - à celle des linguistes "générativistes : la sémiotique vise à rendre compte de tous les langues, et non des seules langues naturelles; et surtout, elle cherche à construire des modèles susceptibles de générer des discours, et non de phrases (grifos dos autores) 3 .

De acordo com a perspectiva de Floch, portanto, o sentido do texto imagético corresponde ao mesmo processo gerativo estabelecido pela proposta teórico-metodológica da semiótica. Mas como as etapas do percurso gerativo de sentido, cujo nível fundamental interliga-se ao narrativo e ao discursivo, poderão ser examinadas se não há uma semiótica linguística materializada? Como seria possível examinar, portanto, o que se denominaria linguagem visual? As análises apresentadas por Floch (1985) compreendem textos constituídos por diferentes linguagens, uma vez que correspon-

\footnotetext{
3 [...] A imagem, por exemplo, não será, para o semioticista, propriamente o signo icônico ou a mensagem composta por signos icônicos; pelo contrário, será tomada como um texto-ocorrência, isto é, como o resultado de um processo complexo de produção do sentido, cujas etapas, na maioria das vezes, não são diferentes daquelas do processo gerador de qualquer outro texto, linguístico ou não. E a própria iconicidade será finalmente definida como a produção de um efeito de sentido de "realidade", característica não de uma dada linguagem ou de um dado signo, mas de um certo tipo de discurso que explora conotações sociais e, entre outras coisas, aquilo que uma dada sociedade pensa de suas diferentes linguagens no que diz respeito a suas respectivas relações com a "realidade". [...] A semiótica é uma teoria do significação que, ao mesmo tempo, é estrutural e gerativa: estrutural no sentido de que, para ela, o sentido nasce da compreensão das diferenças e que, para tanto, trata de construir sistemas de relações que as expliquem: as linguagens serão construídas como sistemas de relações e não como sistemas de signos (o "estruturalismo" semiótico deve ser efetivamente entendido como aquele que assume uma dupla herança epistemológica, saussuriana e hjelmsleviana); gerativa, uma vez que a semiótica representa os sentidos como resultado de um processo de produção, de complexidade crescente, que se apresenta na forma de etapas ou de níveis mais ou menos profundos ou superficiais; por outro lado, a abordagem gerativa, para a semiótica, não pode ser comparada - a não ser por abuso da linguagem - àquela dos linguistas "gerativistas": a semiótica visa dar conta de todas as línguas, e não apenas das línguas naturais; e, acima de tudo, procura construir modelos capazes de gerar os discursos, não as frases (tradução nossa).
} 
Textos de divulgação científica na revista Pesquisa Fapesp: Análise... Arnaldo Cortina

dem à fotografia, à pintura, ao desenho, ao desenho da escrita, ao desenho arquitetônico e à publicidade. Em todos os textos examinados, Floch (1985) verifica como os elementos que compõem as diferentes linguagens por meio das quais são manifestados os textos processam um percurso responsável pela geração de seus sentidos. De forma semelhante, Floch (2002) realiza uma extensa análise da história em quadrinhos de Hergé, Timtim no Tibet.

De acordo com as discussões teórico-metodológicas da semiótica apresentadas nesta seção, o que procuramos verificar na análise da reportagem escolhida foi como os textos das matérias da revista Pesquisa Fapesp são organizados e em que medida realmente atingem o propósito de tornar mais acessíveis as informações que veiculam, e se obtêm sucesso em atrair seu leitor. Nesse sentido, os conceitos de que mais nos valeremos são o de enunciação, de sincretismo e de didatismo, para então, durante a análise propriamente dita, introduzirmos o conceito de prática. Por fim, neste artigo, o que pretendemos examinar são os elementos constituintes da linguagem visual em relação com a verbal. Assim, seguindo a proposta da semiótica discursiva, nosso intuito é estabelecer a relação entre o plano do conteúdo e o plano de expressão, entendendo que este último, no texto visual, será definido "pelas categorias cromáticas, eidéticas, topológicas e matéricas", tal como proposto por Teixeira (2009).

De forma geral, na análise procuramos verificar as estratégias empregadas pelo enunciador do texto da reportagem para a produção do sentido. Dessa forma, o sincretismo resultante da junção dos elementos visuais com o verbal será responsável tanto pelo processo de simplificação da informação, ou de didatização, como denominamos, quanto pelo recurso de sedução à leitura das reportagens. 


\section{Apresentação da revista Pesquisa Fapesp e da repor- tagem para análise}

Os volumes da revista Pesquisa Fapesp são compostos por diferentes sessões que abordam temas diversos. O volume 250, de dezembro de 2016, do qual retiramos o texto da reportagem para análise neste artigo, é constituído pelas seguintes seções:

1. "Fotolab", que no referido número recebe o título "A beleza do conhecimento em imagens", seguido logo abaixo por "Sua pesquisa rende fotos bonitas? Mande para imagempesquisa@fapesp. br. Seu trabalho poderá ser publicado na revista". No número em questão aparece a foto de uma imagem microscópica ampliada da cavidade oral do tubarão-mako;

2. O sumário da revista, com inclusão de fotos;

3. "Cartas", com correspondências enviadas por leitores da revista;

4. "On-line", que informa onde encontrar a revista no formato digital em três versões: português, inglês e espanhol. Além disso, há a divulgação do vídeo do mês e de depoimentos de pesquisadores em programa de rádio, todos realizados pela Fapesp e sediados em seu site;

5. "Carta da editora", assinada por Alexandra Ozório de Almeida, diretora de redação, que faz uma apresentação do volume com destaque para algumas reportagens, em especial para a que aparece na capa do volume;

6. "Boas práticas", seção em que se destaca, no volume 240, a reunião do $4^{\circ}$ Brispe (Brazilian Meeting on Research Integrity, Science and Publication Ethics), principal encontro sobre integridade científica do país. O evento foi realizado no campus da Universidade Federal de Goiás (UFG), nos dias 17 e 18 de novembro de 2016;

7. "Dados", com a apresentação de gráficos que mostram as áreas do conhecimento e as publicações científicas no país; 
Textos de divulgação científica na revista Pesquisa Fapesp: Análise...

8. "Estratégias", seção que conta com quatro breves notícias: "Vencedor do prêmio FCW", "Vem aí o GPS europeu", "Ferramentas para inovação" e "Unesp tem novo reitor", todas com fotografias ilustrativas;

9. "Tecnociência", outra seção com nove breves informações tecnológicas e científicas: "O médico e o café no Brasil do século XIX", "Emaranhamento recorde", "Cupim como aliado da restauração", "Cresce desmatamento na Amazônia", "A lua e a fome dos morcegos", "Malte da cerveja vira guitarra", "Gelo a 105 graus célsius", "O genoma da ginkgo biloba" e "Vacinas conservadas em temperatura ambiente";

10. Reportagem da capa: “Novas batalhas pela prevenção: Reduzir a transmissão do vírus e a discriminação contra os grupos mais vulneráveis à infecção são desafios para deter a epidemia que continua se espalhando";

11. "Entrevista", seção que tem o título "Em busca de jovens brilhantes", decorrente de entrevista realizada com Neil Turok, diretor de instituto canadense de física;

12. "Política C\&T", seção que compreende três reportagens. A primeira, "Estudantes empreendedores", trata das instituições brasileiras com ambiente favorável à inovação; a segunda, "O duelo dos mega-journals", aborda as mudanças no mercado editorial das publicações científicas; a terceira e última, "Impacto além da academia", trata de indicadores alternativos que avaliam o alcance da ciência entre leitores de mídias sociais;

13. "Ciência", seção que, no número 250 da revista, aborda diferentes questões por meio de cinco reportagens e uma entrevista. A primeira reportagem, voltada para a saúde mental, intitulada "O preço da abstinência", aborda processo de investigação em técnica motivacional, na área da psicologia, para conter o consumo de dependentes de crack. A segunda, da área da cardiologia, tem o título "Energia para o coração" e aborda uma investigação sobre efeitos do açúcar na recuperação após infarto. A terceira, no campo da imunologia, consiste na reportagem intitulada "Quando 
Textos de divulgação científica na revista Pesquisa Fapesp: Análise... Arnaldo Cortina

as defesas destroem o cérebro" e trata de descobertas decorrentes de pesquisa sobre inflamação no corpo humano associada à malária cerebral. A quarta aborda uma investigação geológica que discute a hipótese de que as riquezas minerais da Amazônia associam-se à existência de vulcões na região há milhares de anos e intitula-se "Erupções preciosas". A quinta e última reportagem dessa seção vincula-se à geofísica e, sob o título "O elemento subterrâneo", trata da descoberta da presença de carbono nas profundezas do planeta Terra. Em seguida a essas cinco reportagens aparece uma entrevista com a física argentina Gabriela Gonzáles, radicada nos EUA e trabalhando na Universidade Estadual de Lousiana, que aborda a detecção das ondas gravitacionais e intitula-se "Quando o espaço se curva".

14. "Tecnologia", seção composta por três reportagens. A primeira, "Soluções para os cadeirantes", trata de engenharia biomédica para aperfeiçoamento de cadeiras de rodas de que dependem algumas pessoas sem condições normais de locomoção. A segunda, "Além do horizonte", volta-se para a pesquisa empresarial ao tratar da construção de radares para localização de embarcações no alto mar. A última reportagem, "Proteção para recém-nascidos", pertence à área médica e trata da invenção de capacete que auxilia bebês com deficiência de oxigenação no cérebro.

15. "Humanidades" é a última seção de reportagens da revista e é constituída por três textos. O primeiro, dentro da área de antropologia forense, "Uma luta contra o desaparecimento", trata de projeto para identificação de desaparecidos durante o período da ditadura militar brasileira. A seguinte, "A permanência de Hannah Arentdt", trata dos 110 anos de nascimento de Hannah Arendt segundo a perspectiva da teoria política. A terceira, no âmbito da literatura, "As flutuações de Dostoievski", faz uma discussão sobre o prestígio de escritores russos na primeira era do ex-presidente Getúlio Vargas.

16. "Memória", seção que corresponde a uma reportagem comemorativa sobre o livro $O$ doutor Benignus, inspirado nas obras 
Textos de divulgação científica na revista Pesquisa Fapesp: Análise... Arnaldo Cortina

de Júlio Verne e escrito por Augusto Emílio Zaluar, o então primeiro romance de ficção científica publicado no Brasil.

17. "Resenha", sob o título "O trágico das relações raciais no Brasil", seção em que aparece uma resenha do livro $O$ intelectual feiticeiro: Edison Carneiro e o campo de estudos das relações raciais brasileiras, escrito por Gustavo Rossi e publicado pela Editora da Unicamp;

18. "Obituário", sob o título "Uma vida pela anatomia", faz uma homenagem à Berta Lange de Morretes, professora e pesquisadora na área de Botânica, falecida em 30 de novembro de 2016 aos 99 anos;

19. "Carreiras", última seção da revista, que traz uma reportagem ligada à área da educação e que tem como título "Natureza no museu", apresenta um diagnóstico do taxidermista, profissional que auxilia nos estudos taxonômicos, ecológicos, biogeográficos e ambientais.

Na última página da revista e na sua contracapa há espaço para classificados ${ }^{4}$. Além disso, a disposição dos quatro temas amplos (seções 12, 13, 14 e 15) segue sempre uma mesma estrutura, isto é, consiste numa reportagem produzida por um jornalista da equipe da revista ou por um freelance que lhe vende o trabalho, sempre com fotos, infográficos e desenhos, além de cada volume conter uma reportagem em destaque, que é apresentada na capa da revista e desenvolvida no seu interior, com a mesma organização das reportagens que compõem os temas amplos. No caso do volume 250, portanto, o tema da capa consiste em mostrar a difusão da Aids (Acquired Immunodeficiency Syndrome - Síndrome de Imunodeficiência Adquirida) no Brasil e no mundo e as formas de prevenção à doença.

A apresentação empreendida aqui, do volume da revista do qual selecionamos o texto a ser examinado, corresponde a um retrato do universo dos demais volumes da revista que abarcam o período da pesquisa. A distribuição das diferentes seções é sem-

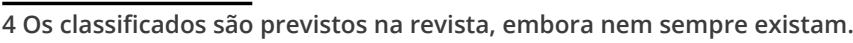


Textos de divulgação científica na revista Pesquisa Fapesp: Análise... Arnaldo Cortina

pre a mesma, alterando-se apenas o número de reportagens que constitui determinada seção e, evidentemente, os temas para cada uma delas. Dentre as seções centrais da revista, "Política C\&T", "Ciência”, "Tecnologia”, "Humanidades" e "Memória”, ora aparecem mais reportagens, ora menos, em cada uma delas. Normalmente a seção com menor número de textos é a de "Humanidades", pois, como se pode observar, Ciência e Tecnologia é uma tônica da revista.

A revista Pesquisa Fapesp, portanto, constrói-se enquanto uma prática semiótica cujo sujeito da enunciação constitui-se por um enunciador que representa a voz da revista e é produzido em função de uma imagem de leitor, seu enunciatário, a quem apresenta diferentes informações decorrentes do universo da pesquisa científica - resultante de trabalhos realizados por pesquisadores e por grupos de pesquisa financiados, na maioria dos casos pela própria Fapesp ou por outras instituições nacionais ou internacionais. Como o universo temático da revista é bastante abrangente, procurando abarcar diferentes áreas do público universitário ou que tenha interesses científicos, faz vasto uso dos recursos visuais para tornar mais acessível todas as informações que propõe divulgar. Como já comentado em outros artigos por nós publicados, o fato de os textos de reportagem serem produzidos por uma equipe de jornalistas e não particularmente pelo próprio pesquisador envolvido com o tema é uma forma de didatizar o conteúdo. De acordo com a entrevista realizada com o editor da revista, anteriormente mencionada, os jornalistas constantemente recorrem a pesquisadores ou a grupo de pesquisa que desenvolvam trabaIhos com os temas das reportagens pelas quais são responsáveis. Os pesquisadores chegam, muitas vezes, a ler o texto produzido pelos jornalistas para emitirem opiniões ou fazerem correções, mas nunca produzem diretamente os textos.

Por essas razões, a produção de cada volume da revista é realizada por uma grande equipe de trabalho constituída por um Conselho Editorial, por um Comitê Científico, por um coordenador científico, por uma diretora de redação, por um editor-chefe, 
Textos de divulgação científica na revista Pesquisa Fapesp: Análise...

Arnaldo Cortina

por um corpo de editores, de revisores, de responsáveis pela arte, pelas mídias eletrônicas, por fotógrafos e por diversos jornalistas colaboradores.

\section{Análise da reportagem "Aids. Reforçando a prevenção"}

1. Capa

Figura 1 - Capa reportagem "Aids. Reforçando a prevenção" da Revista Pesquisa Fapesp.

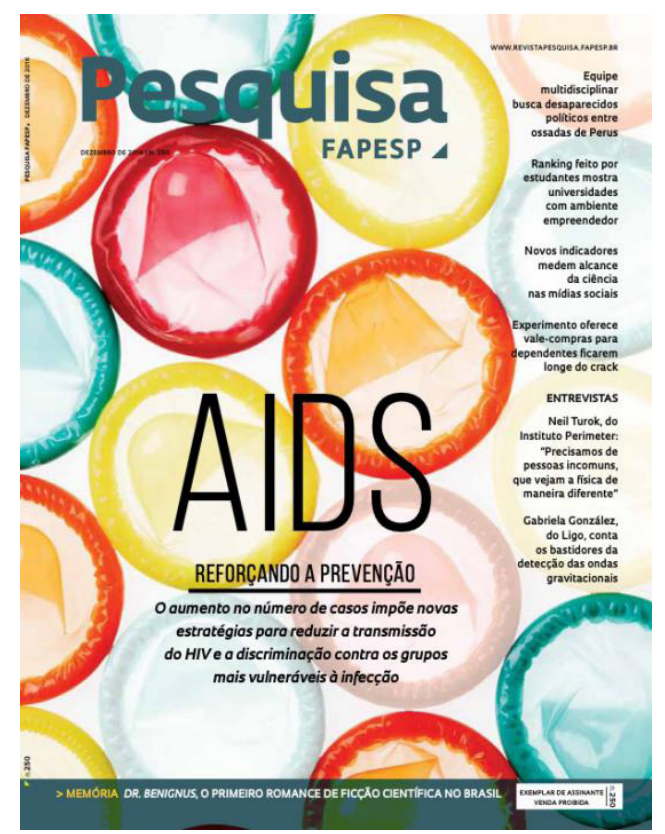

Fonte: Revista Pesquisa Fapesp, vol. 250, dez. 2016.

A capa do volume 250 da revista Pesquisa Fapesp apresenta um fundo branco sobre o qual estão dispostos vários preservativos, de diferentes cores, utilizados pelos homens durante o ato sexual. Os preservativos funcionaram inicialmente como agentes contraceptivos, mas, durante o período de eclosão da Aids, tornaram-se o método mais eficaz de combate à propagação do vírus entre os seres humanos. 
Textos de divulgação científica na revista Pesquisa Fapesp: Análise... Arnaldo Cortina

Na parte superior da capa aparece o nome da revista: Pesquisa FAPESP. Na parte inferior central dessa mesma capa há o nome da doença (AIDS) em maiúsculas com as letras em tamanho aumentado, logo abaixo a expressão grifada "REFORÇANDO A PREVENÇÃO" também em maiúsculas, mas com letras menores que a sigla da doença na parte de cima. Em seguida, negritada e em itálico, aparece a seguinte informação: "O aumento do número de casos impõe novas estratégias para reduzir a transmissão do HIV e a discriminação contra os grupos mais vulneráveis à infecção". Esse é o destaque dado a uma das reportagens que será apresentada no interior da revista. À direita, nessa mesma capa, desde a parte superior até quase o final da folha, recebem destaque menor algumas das reportagens que compõem a revista.

Do ponto de vista visual, o texto da capa é composto, como já dito, por preservativos coloridos, dispostos uns ao lado dos outros, sem que estejam dentro das embalagens em que normalmente são vendidos ao consumidor ou distribuídos gratuitamente à população pelos órgãos de saúde.

Observado de cima a baixo, o texto visual construído na capa da revista remete aos confetes de papel que são jogados ao ar e caem ao chão, muito característicos das festas carnavalescas. Essa imagem representa uma foto em que, numa festa de carnaval, os confetes arremessados tombam ao chão ou nas cabeças dos foliões. Como se uma câmera ampliasse a imagem, a queda dos confetes coloridos é, de certa forma, reproduzida pela cena dos preservativos coloridos dispostos em primeiro plano na capa da revista. Ao se associar aos confetes de papel, portanto, a imagem remete às paradas LGBTQ+ que acontecem anualmente em várias cidades do país. As cores do arco-íris estampam as bandeiras do movimento LGBTQ+ e os confetes estão também a elas associados. Dessa maneira, portanto, o efeito de sentido criado é o do contexto da festa e, especificamente, da festa mais popular do público homossexual que a reportagem apontará como o de maior risco, pois apresenta o aumento mais acentuado dos novos casos de contaminação do vírus HIV. 
Textos de divulgação científica na revista Pesquisa Fapesp: Análise...

No texto do subtítulo da notícia destacada na capa está escrito que, em decorrência da intensificação dos casos de infecção pelos vírus da AIDS, os setores da saúde têm procurado estratégias para "reduzir a transmissão do HIV e a discriminação contra os grupos mais vulneráveis à infecção". Embora não haja referência explícita ao grupo LGBTQ+, os termos "discriminação" e "grupos mais vulneráveis" associados à imagem que compõe essa capa da revista implicitam o setor LGBTQ+.

2. A reportagem

Figura 2 - Páginas 18 e 19 da revista Pesquisa Fapesp

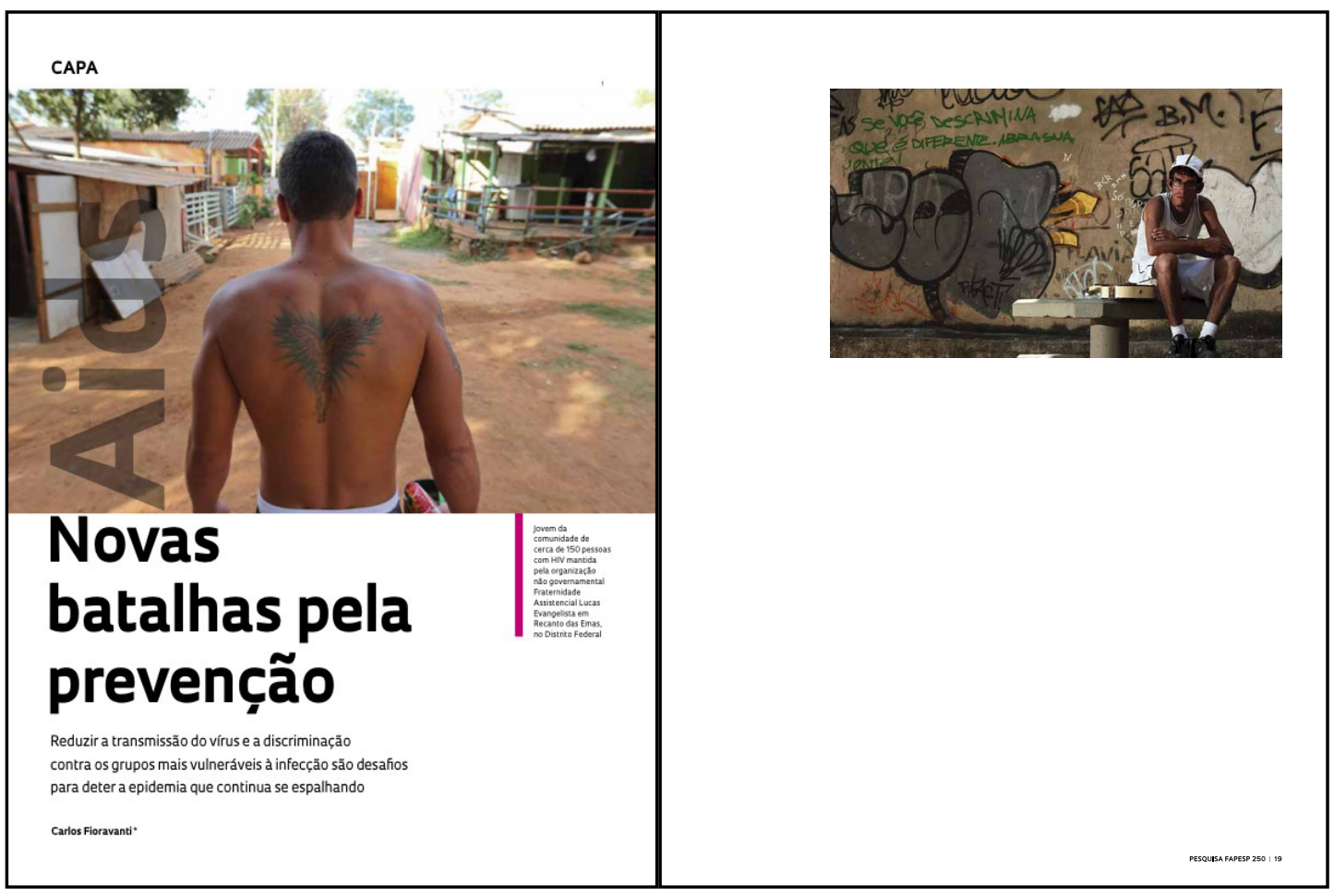

Fonte: Revista Pesquisa Fapesp, vol. 250, dez. 2016.

Internamente à revista, a reportagem tem como título em letras grandes: "Novas batalhas pela prevenção". Logo abaixo, como subtítulo, aparece em letras menores: "Reduzir a transmissão do vírus e a discriminação contra os grupos mais vulneráveis à infec- 
Textos de divulgação científica na revista Pesquisa Fapesp: Análise...

ção são desafios para deter a epidemia que continua se espalhando", o que significa uma repetição do que havia sido dito na capa da revista.

No texto escrito que corresponde à reportagem, porém, há referência explícita ao comportamento homossexual do portador do vírus do HIV, quando inicialmente se afirma que centros de pesquisa e de atendimento médico de São Paulo, do Rio de Janeiro e de Porto Alegre examinam "dois grupos com alto risco de infecção - homens que fazem sexo com homens (homo ou bissexuais) ou travestis e mulheres transexuais (que se identificam como sendo do sexo feminino, embora ao nascer tenham sido designadas como do sexo masculino)" (p. 19).

Nas páginas 18 e 19 há duas fotos. A primeira, à página 18, registra um rapaz de costas e na legenda, logo abaixo, diz-se que se trata de "jovem da comunidade de cerca de 150 pessoas com HIV mantida pela organização não governamental Fraternidade Assistencial Lucas Evangelista em Recanto das Emas, no Distrito Federal". A segunda, à página 19, reproduz um outro rapaz sentado no banco de uma praça, com uma parede pichada ao fundo, em que se pode ler, entre várias coisas, "Se você discrimina quem é diferente, abra sua mente". Na legenda, ao lado esquerdo da foto, está dito o seguinte: "Leandro Fernandes Jacob, HIV positivo, já deu palestras sobre suas experiências de vida para jogadores de vários clubes de futebol". Embora nas legendas que acompanham as fotos não haja qualquer referência à orientação sexual dos rapazes retratados, o contexto da reportagem remete à questão da homossexualidade, pois, como dito anteriormente, o texto inicia-se mencionando centros que pesquisam a evolução dos casos de infecção pelo vírus da AIDS em grupos de homens que fazem sexo com homens, quer conservem o gênero designado em seu nascimento ou se identifiquem com outro. Essa é, por exemplo, a maneira como o elemento visual está relacionado ao verbal. Embora não se diga especificamente que os homens reproduzidos nas imagens identificam-se como homossexuais, o contexto 
Textos de divulgação científica na revista Pesquisa Fapesp: Análise...

da reportagem e as informações que acompanham essas figuras conduzem a compreensão do leitor do artigo da revista.

Figura 3 - Páginas 20 e 21 da revista Pesquisa Fapesp

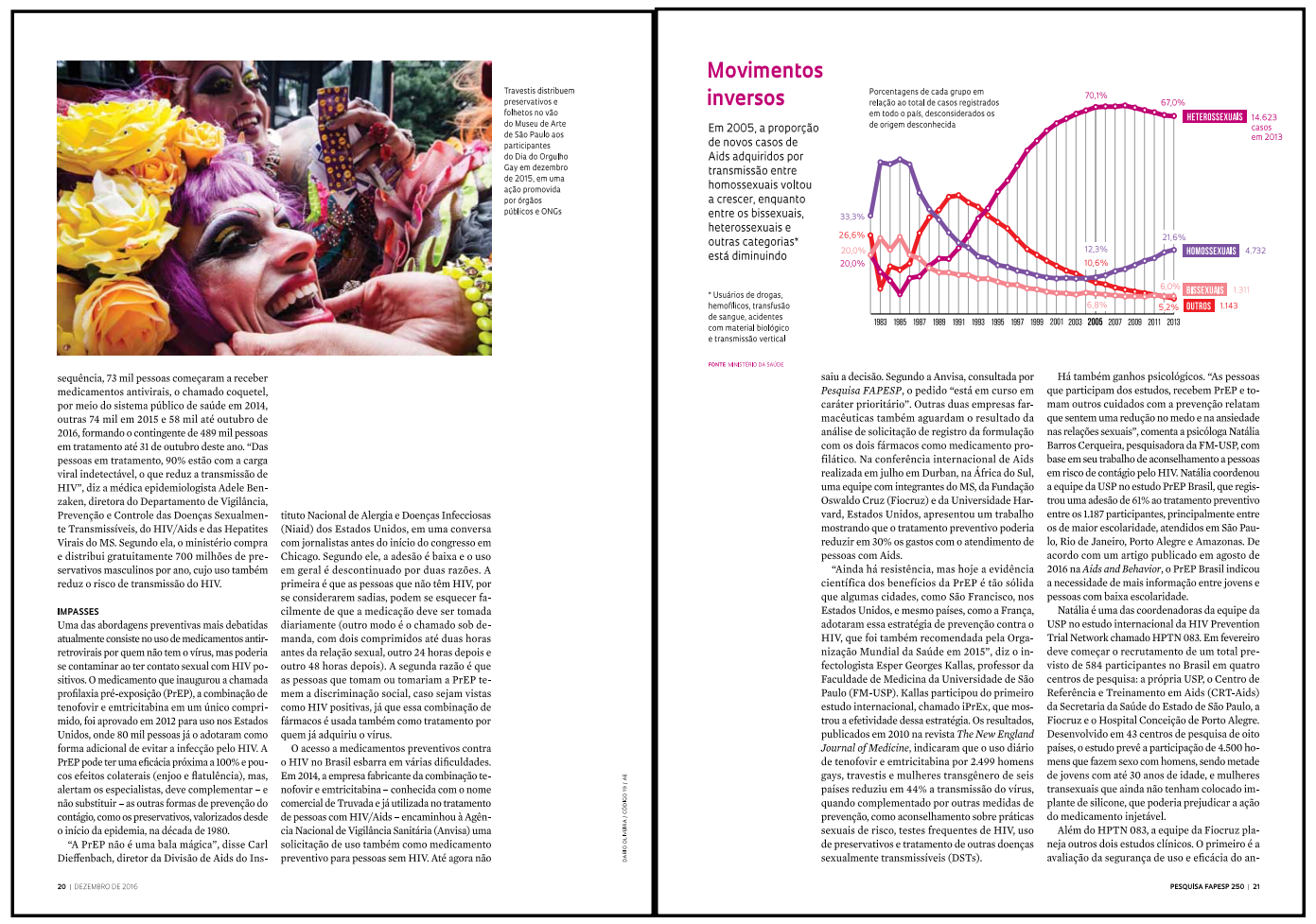

Fonte: Revista Pesquisa Fapesp, vol. 250, dez. 2016.

À página 20, a foto de ilustração é uma referência explícita ao público LGBTQ+, pois apresenta closes de duas travestis que distribuem preservativos masculinos na manifestação do Dia do Orgulho Gay de São Paulo em 2015. Novamente o colorido é ressaltado pelas flores na cabeça dos rostos da foto, pelo cabelo tingido e pela maquiagem acentuada. Na foto há um jogo cromático intenso em que estão realçadas, principalmente, as cores amarela, matizes de roxo, violeta, púrpura e lilás, sendo que, inclusive, a embalagem dos preservativos distribuídos por uma das travestis tem fundo roxo e várias esferas amarelas com destaque ao ponto de exclamação que remete ao falo, com os dizeres, também em amarelo, "vista-se" em letra maior e abaixo, em letras menores, 
Textos de divulgação científica na revista Pesquisa Fapesp: Análise... Arnaldo Cortina

"use sempre camisinha". Dessa forma, tanto o texto verbal quanto o visual ressaltam o público alvo de pesquisas de órgãos de saúde pública ou de universidades que se preocupam com o incremento de casos de infecção por HIV. Esse público, como dito, é o LGBTQ+.

À página 21 aparece um infográfico que mostra $\mathrm{O}$ comportamento de quatro grupos de pessoas infectados pelo HIV: 1) heterossexuais, 2) homossexuais, 3) bissexuais e 4) outros, que compreende os usuários de drogas, os hemofílicos, as pessoas que fizeram transfusão de sangue e as pessoas que foram infectadas por material biológico ou por transmissão vertical (doença passada ao filho pela mãe durante a gestação).

Esse infográfico mostra a porcentagem de incidência do vírus HIV nos quatro grupos acima referidos, desde 1983, quando começaram a ser registradas as ocorrências, até 2013. No início dos registros, entre 1983 e 1987, o maior índice de casos de soropositivos (quase $50 \%$ ) está realmente no grupo dos denominados homossexuais, mas depois eles vão caindo vertiginosamente e, a partir de 2005, quando atingiu o percentual mais baixo (12,3\%), até 2013, começam a apresentar uma nova curva de crescimento (21,6\%). No grupo dos bissexuais, o maior índice auferido é o de 1985 (por volta de 26\%), depois diminui, entre 2005 (6,8\%) e 2013 (6\%). Para o grupo dos "outros", o ápice dos casos de infecção pelo vírus registrado ocorre em 1991 (por volta de 35\%) e depois cai bastante entre $2005(10,6 \%)$ e 2013 (5,2\%). Já entre o grupo dos heterossexuais, cujo menor registro é o de 1985 (menos de 10\%), ocorre um aumento exponencial até 2005 (70,1\%), mantendo-se alto até 2007, mas caindo em 2013 (67\%). O que se constata pelo infográfico é que realmente houve queda nos casos de três grupos sobre os quais há registro de ocorrência de infecção pelo vírus HIV, os heterossexuais $(-3,1 \%)$, os bissexuais $(-0,8 \%)$ e os outros $(-5,4 \%)$, e um aumento no caso do grupo dos homossexuais $(9,3 \%)$.

A reportagem, por sua vez, não faz referência, em nenhum momento, aos casos de ocorrência do HIV entre os heterossexuais e centra-se em destacar o aumento de casos no grupo dos homossexuais. Realmente há a constatação, pelos estudos realizados, de 
Textos de divulgação científica na revista Pesquisa Fapesp: Análise... Arnaldo Cortina

que esse incremento nos casos do universo homossexual deve-se à produção de fármacos que eliminam a possibilidade de morte, tal como ocorreu no início da epidemia nos anos 1980. Além de remédios que podem ser ministrados àqueles que contraíram o vírus, as pesquisas chegam à produção da Profilaxia Pré-Exposição (PrEP), que pode ser consumida por aqueles que mantêm relações com pessoas portadoras do vírus HIV. O que fica ressaltado pela pesquisa é que a possibilidade do tratamento e do pré-tratamento produz um relaxamento na prevenção, levando às pessoas do grupo dos homossexuais a se relacionarem sexualmente sem o uso dos preservativos. Portanto, trata-se de um fato que deve ser combatido, mas seria importante também apontar que a maior parte dos casos de incidência de HIV está no grupo dos heterossexuais (67\%) e não no dos homossexuais (21,6\%), porque a infecção entre os heterossexuais é bastante alta. Esse fato, porém, é apagado na reportagem.

Figura 4 - Páginas 22 e 23 da revista Pesquisa Fapesp

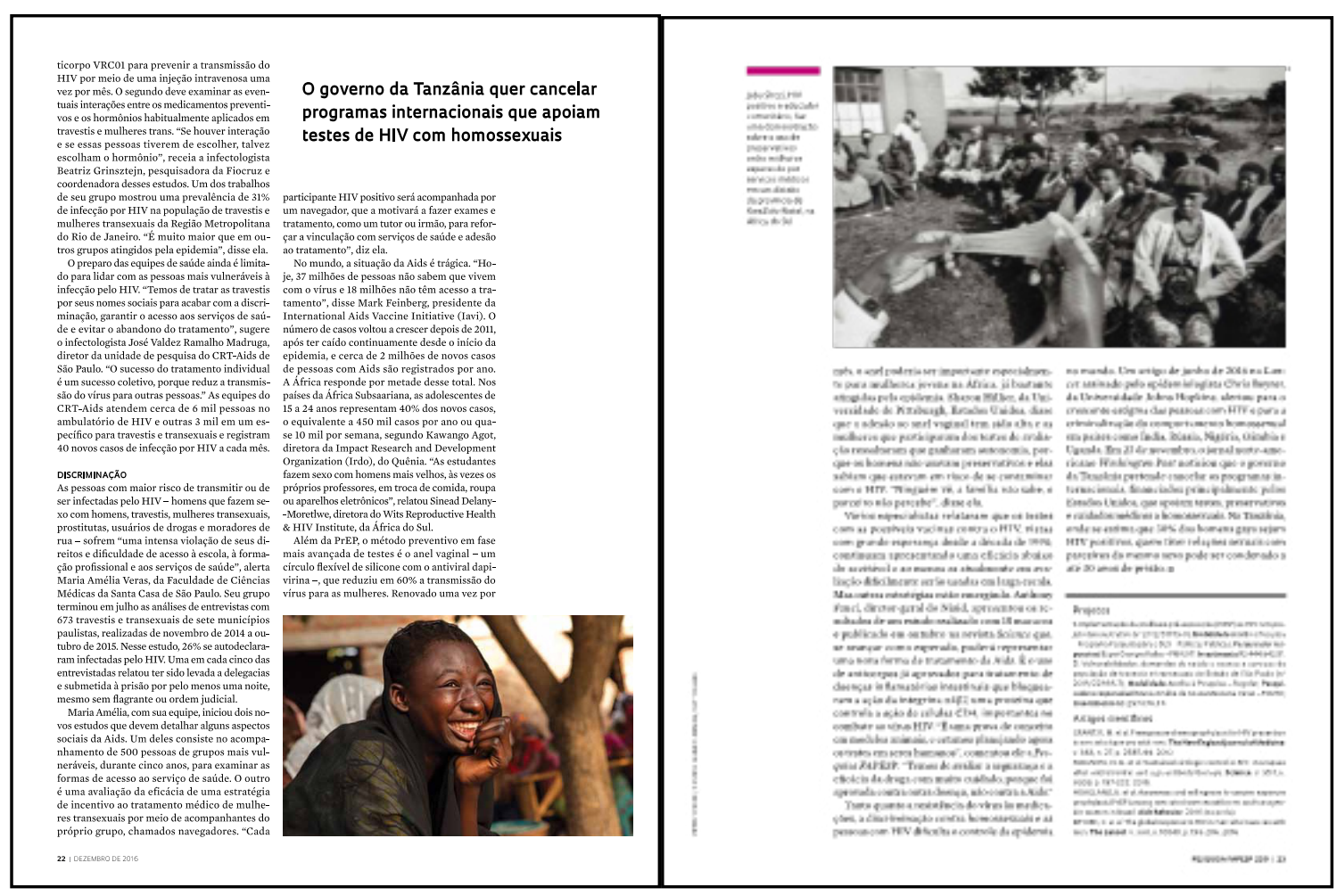

Fonte: Revista Pesquisa Fapesp, vol. 250, dez. 2016. 
Textos de divulgação científica na revista Pesquisa Fapesp: Análise... Arnaldo Cortina

Ao final da reportagem, o texto aborda o tema da discriminação remetendo-se a um trabalho realizado por uma equipe da Faculdade de Ciências Médicas da Santa Casa de São Paulo e destaca que o grupo formado por homens que fazem sexo com homens, travestis, mulheres transexuais, usuários de drogas e moradores de rua sofre violência policial, tem dificuldades de acesso à escola, à formação profissional e aos serviços de saúde. Por essa razão constitui-se num grupo de alto risco, no qual se tem verificado o aumento de casos de infecção pelo HIV.

Nesse item final da reportagem é destacada a situação crítica de países do continente africano em que os casos de infecção pelo HIV correspondem à metade de todos os casos que se identifica por ano no mundo. Além da utilização do PrEP como forma de evitar o contágio com o vírus, a reportagem destaca o uso do anel vaginal (um círculo flexível de silicone com o antiviral dapivirina) como outra forma de evitar o contágio, que, ao ser renovado mensalmente, poderia contribuir para a diminuição do contágio pelo vírus entre as mulheres jovens da África, as mais atingidas pelo vírus. Nesse momento do texto da reportagem, portanto, é discutida a situação das mulheres africanas que não fazem parte dos grupos dos homossexuais, bissexuais, e outros, apontados pelo infográfico da página 21, mas em nenhum momento aponta-se que se trata de grupo de heterossexuais. Nessa parte da reportagem aparecem mais duas fotos, uma colorida e outra em preto e branco. A primeira dessas fotos registra, em close, uma menina negra da cidade de Monduo, na República do Chade, país do centro-norte da África, que participa de atividade extracurricular sobre prevenção de Aids. A segunda foca em primeiro plano as mãos de Jabu Shezi, um educador comunitário portador do HIV, que segura um preservativo, ensinando para um grupo de mulheres negras como deve ser utilizado; elas estão no plano de fundo da foto, aguardando para serem atendidas pelo serviço médico, na província costeira de KwaZulu-Natal, na África do Sul. 
Textos de divulgação científica na revista Pesquisa Fapesp: Análise... Arnaldo Cortina

\section{Conclusão}

Do ponto de vista semiótico, o que se pode dizer do texto da reportagem da revista Pesquisa Fapesp é que os elementos visuais nele presentes refletem e evidenciam aquilo que a parte verbal está apresentando. Diríamos, portanto, que se trata de um recurso intensificador do dito, que cumpre o papel de materializar as informações passadas. Apenas o esquema apontado à página $21 \mathrm{da}$ revista parece revelar que o enunciador do texto da reportagem destaca os problemas que envolvem o chamado "grupo de risco", em que está identificado um aumento de ocorrências de infecção pelo vírus, ao mesmo tempo que é o que mais sofre discriminação social.

Do ponto de vista da organização narrativa, o que o enunciado materializa é o fato de as pesquisas científicas produzirem medicamentos que podem combater com mais eficácia a disseminação do vírus HIV responsável pelos casos de AIDS, ao mesmo tempo que isso propicia um aumento de incidência da doença nos grupos sociais de homens que fazem sexo com homens e de travestis e mulheres transexuais. A contradição está no fato de que, embora tenham efeito terapêutico, os novos medicamentos descobertos acabam impulsionando o aumento de casos de pessoas infectadas, uma vez que ao se sentirem protegidas pela possibilidade de os utilizarem, relaxam os métodos de prevenção.

As cinco fotos que ilustram a reportagem têm características distintas. As duas primeiras, às páginas 18 e 19 da revista, estampam as figuras de dois homens portadores do vírus, cuja legenda indica pertencerem aos grupos de risco, e são constituídas por jogos de sombras, o que dá um aspecto mais escuro aos ambientes. As duas últimas, às páginas 22 e 23, seguem um padrão semelhante, sendo que a última, diferentemente das anteriores, apresenta-se em preto e branco. Já a terceira foto, à página 20, e o infográfico, à página 21, são coloridos, remetendo, como citado anteriormente, à festa e ao carnaval. O infográfico, por sua vez, destaca um dado 
Textos de divulgação científica na revista Pesquisa Fapesp: Análise... Arnaldo Cortina

importante que consiste em evidenciar o aumento de casos de contaminação pelo HIV no grupo dos homossexuais, mas não ressalta a alta incidência de casos de HIV no grupo não considerado de risco (os heterossexuais). Ao tocar parcialmente nessa questão, a enunciação reporta-se ao caso de mulheres africanas, que, no caso, sofrem outras formas de discriminação, pois são mulheres, são pobres e são negras.

Essas conclusões a que chegamos neste trabalho, embora digam respeito a uma reportagem que aborda um problema específico, seguem um esquema de apresentação que se repete ao longo dos doze números que compõem o córpus da pesquisa. Embora evidentemente tratem de objetos distintos, o procedimento de aproximação entre o verbal e o visual é o mesmo, qual seja, atrair o leitor para as mais diferentes temáticas e tornar mais acessíveis as informações veiculadas por elas. Nesse sentido, a prática da construção do texto sincrético é uma marca constante da revista Pesquisa Fapesp e é pautada por seus objetivos aqui ressaltados.

\section{Referências Bibliográficas}

HOUAISS, Antônio. Dicionário Houaiss de língua portuguesa. Rio de Janeiro: Objetiva, 1 a ed., 2009.

FLOCH, Jean-Marie. Petites mythologies de l'œil et de l'esprit. Pour une sémiotique plastique. Amsterdam : Hadès-Benjamins, 1985.

FLOCH, Jean-Marie. Une lecture de Tintin au Tibet. Paris: PUF, 2002.

GREIMAS, Algirdas Julien; COURTÉS, Joseph. Tradução de Alceu Dias Lima et alii. Dicionário de semiótica. São Paulo: Contexto, 2008.

HJELMSLEV, LOUIS. Prolegômenos a uma teoria da linguagem. Tradução de J. Teixeira Coelho Netto, São Paulo: Perspectiva, 2009. TEIXEIRA, Lúcia. “Para uma metodologia de análise de textos verbovisuais". In: OLIVEIRA, Ana Cláudia de; TEIXEIRA, Lúcia (Org.). Linguagens 
Textos de divulgação científica na revista Pesquisa Fapesp: Análise... Arnaldo Cortina

na comunicação. Desenvolvimentos de semiótica sincrética. São Paulo: Estação das Letras e Cores, 2009, p. 41-77. 